\title{
Antibody-modified conduits for highly selective cytokine elimination from blood
}

\author{
J. Brian McAlvin, ${ }^{1,2}$ Ryan G. Wylie, ${ }^{1}$ Krithika Ramchander, ${ }^{3}$ Minh T. Nguyen, ${ }^{1}$ Charles K. Lok, ${ }^{1}$ Morgan \\ Moroi, ${ }^{1}$ Andre Shomorony, ${ }^{1}$ Nikolay V. Vasilyev, ${ }^{4}$ Patrick Armstrong, ${ }^{1}$ Jason Yang, ${ }^{3}$ Alexander M. \\ Lieber, ${ }^{1}$ Obiajulu S. Okonkwo, ${ }^{1}$ Rohit Karnik, ${ }^{5}$ and Daniel S. Kohane ${ }^{1}$ \\ 'Laboratory for Biomaterials and Drug Delivery, Department of Anesthesiology, and 'Department of Medicine, Division of \\ Medicine Critical Care, Harvard Medical School, Boston Children's Hospital, Boston, Massachusetts, USA. ${ }^{3}$ Massachusetts \\ Institute of Technology, Cambridge, Massachusetts, USA. 'Department of Cardiac Surgery, Boston Children's Hospital, \\ Harvard Medical School, Boston, Massachusetts, USA. ${ }^{5}$ Department of Mechanical Engineering, Massachusetts Institute \\ of Technology, Cambridge, Massachusetts, USA.
}

Cytokines play an important role in dysregulated immune responses to infection, pancreatitis, ischemia/reperfusion injury, burns, hemorrhage, cardiopulmonary bypass, trauma, and many other diseases. Moreover, the imbalance between inflammatory and antiinflammatory cytokines can have deleterious effects. Here, we demonstrated highly selective blood-filtering devices antibody-modified conduits (AMCs) - that selectively eliminate multiple specific deleterious cytokines in vitro. AMCs functionalized with antibodies against human vascular endothelial growth factor $A$ or tumor necrosis factor $\alpha$ (TNF- $\alpha$ ) selectively eliminated the target cytokines from human blood in vitro and maintained them in reduced states even in the face of ongoing infusion at supraphysiologic rates. We characterized the variables that determine AMC performance, using anti-human TNF- $\alpha$ AMCs to eliminate recombinant human TNF- $\alpha$. Finally, we demonstrated selective cytokine elimination in vivo by filtering interleukin $1 \beta$ from rats with lipopolysaccharideinduced hypercytokinemia.

Conflict of interest: The authors have declared that no conflict of interest exists.

Submitted: March 19, 2018

Accepted: May 25, 2018

Published: July 12, 2018

\section{Reference information:} JCI Insight. 2018;3(13):e121133. https://doi.org/10.1172/jici. insight.121133.

\section{Introduction}

Many circulating molecules have been implicated in disease pathogenesis and their selective removal from the circulation could be clinically useful. A variety of strategies have been developed for removing such molecules, depending on their physicochemical properties (molecular weight, hydrophobicity, etc.). In many cases, the removal process can be fairly nonspecific $(1,2)$ (e.g., dialysis-like therapies). In most cases, the only goal of treatment is to remove the harmful molecules from the bloodstream; their functional absence thereafter (e.g., with antibody treatments) is not harmful in itself. Treatment of hypercytokinemia is different in several respects. First, nonspecific cytokine elimination does not improve clinical outcomes (2). Second, nonspecific strategies eliminate most cytokines (1-3), whether they are harmful or even potentially beneficial (4). Third, they do not address the fact that specific cytokines might be harmful at one time and beneficial at another (5). Nonspecific methods may also lead to unwanted removal of desirable molecules such as therapeutic antibiotics (6) and clotting factors (7); this can be problematic in patients with hypercytokinemia, who often require antibiotics (8) and are often coagulopathic (9). A cytokine-specific and temporally controlled method for removing cytokines would potentially be beneficial in treating a wide range of conditions with dysregulated immune responses to infection (10-12), pancreatitis (13), ischemia/reperfusion injury (14), burns (15), hemorrhage (16), cardiopulmonary bypass $(17,18)$, trauma (19), and many other diseases. Sepsis, which is defined as life-threatening organ dysfunction caused by a dysregulated host response to infection (20) is a common example (21).

Here, we report the development of blood-filtering devices, for incorporation within extracorporeal circuits, that selectively filter individual cytokines from circulating blood (Figure 1A). Antibodies against specific cytokines were tethered to the luminal surfaces of silicone-based conduits (antibody-modified conduits [AMCs]) (Figure 1B). Parameters such as AMC geometry, quantity of antibody, cross-linking molecules, and flow rate were tailored to control the rate and quantity of cytokine removal, and a model was developed 
A

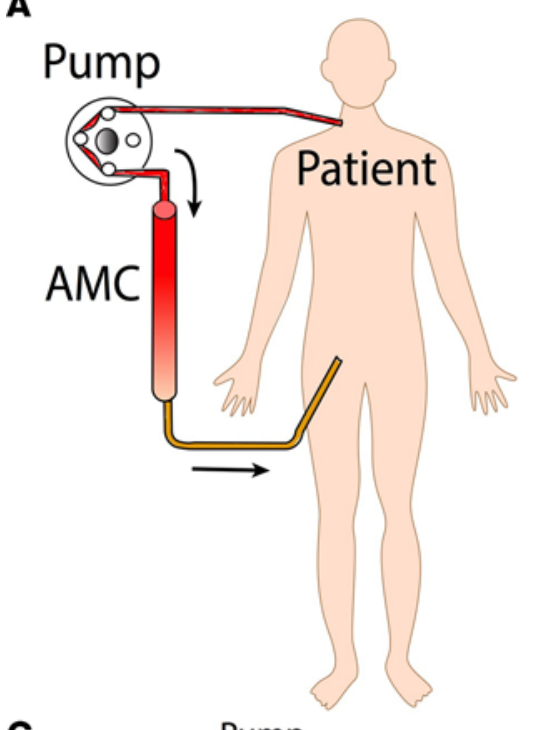

B

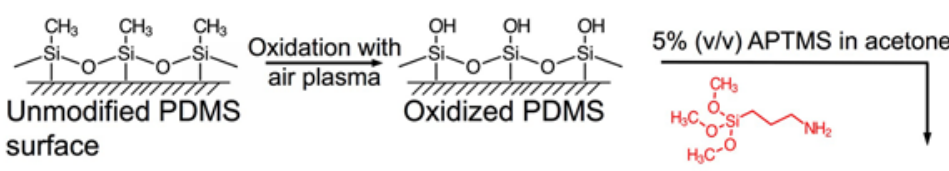

surface
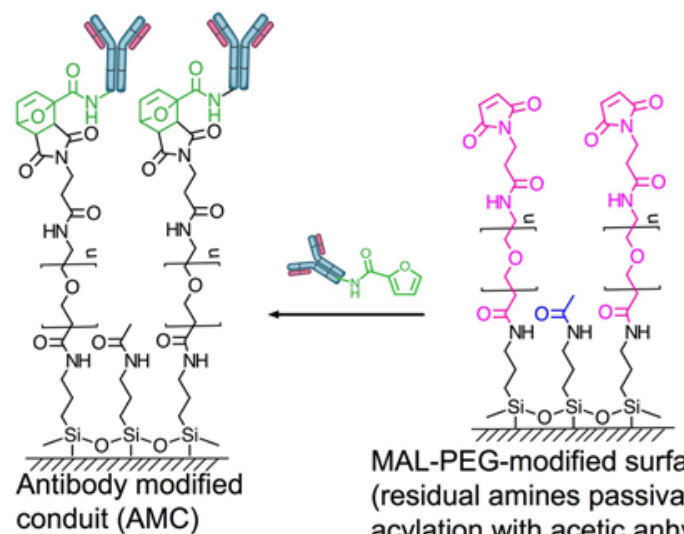

MAL-PEG-modified surface

(residual amines passivated by

acylation with acetic anhydride)

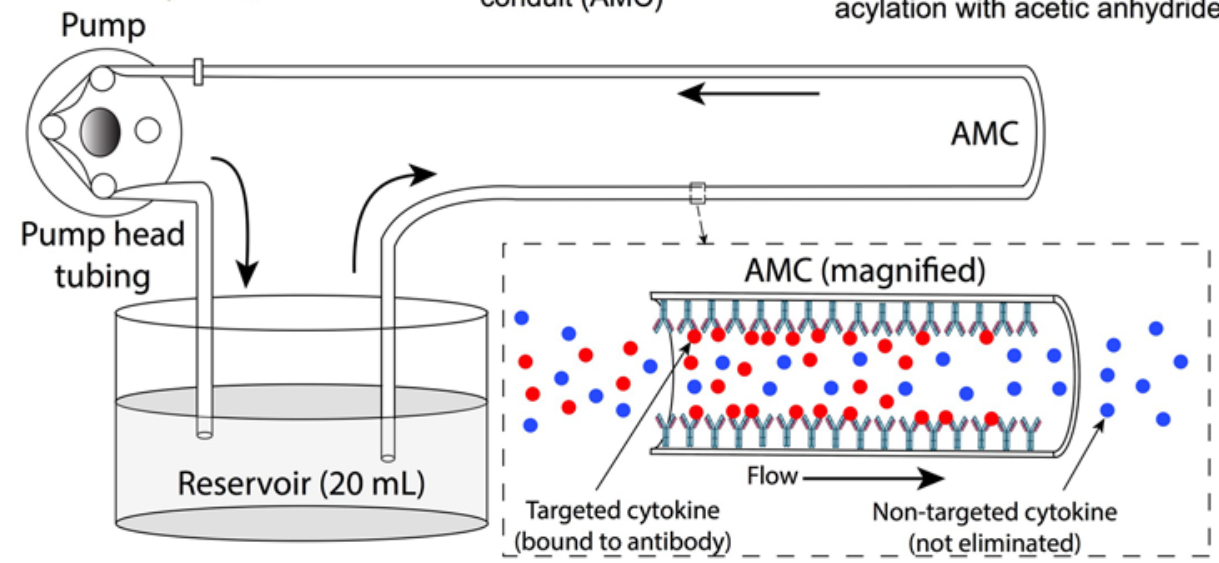

Figure 1. Antibody-modified conduits (AMCs). (A) Schematic of extracorporeal selective cytokine elimination with AMCs. (B) Reaction scheme for AMC synthesis. PDMS, poly(dimethylsiloxane); APTMS, (3-aminopropyl)trimethoxy-silane; NHS-PEG - -MAL, poly(ethylene glycol) with $N$-hydroxysuccinimide ester and maleimide moieties, where $n$ is the PEG molecular weight; MES, 2-( $N$-morpholino)ethanesulfonic acid. (C) Schematic of the experimental setup for selective elimination of cytokines by AMCs. Cytokine-containing solutions were circulated through AMCs by a peristaltic pump and cytokine concentrations in the fluid were measured over time. Arrows represent direction of flow.

to predict the rate of removal based on these parameters. We investigated the ability of AMCs to selectively eliminate cytokines from human whole blood in vitro and their ability to clear the circulation of specific cytokines in vivo in rats administered intravenous lipopolysaccharide (LPS) injection to induce hypercytokinemia.

\section{Results}

$A M C$ preparation. AMCs were prepared by grafting anti-cytokine antibodies onto the luminal surfaces of poly(dimethylsiloxane) (PDMS) conduits through sequential reactions (Figure 1B). The luminal surfaces of PDMS tubes were oxidized to allow reaction with (3-aminopropyl)trimethoxy-silane (APTMS), which in turn would allow attachment of a PEG linker to which an antibody would be bound (see Methods for details). Experimental parameters for each reaction step in that process were examined (Supplemental Note 1; supplemental material available online with this article; https://doi.org/10.1172/jci.insight.121133DS1) to develop the reaction scheme shown in Figure 1B. As a result of that examination, plasma oxidation was selected over solution phase oxidation (Supplemental Figure 1.1A); solvent extraction of unreacted PDMS oligomers was not performed before oxidation (Supplemental Figure 1.1A); oxidized circuits were reacted with $5 \%(\mathrm{v} / \mathrm{v})$ APTMS in acetone to coat the surface with primary amine groups (Supplemental Figure 1.1B); PEGylation was performed at $\mathrm{pH} 8.5$ (Supplemental Figure 1.1C); antibodies were then conjugated onto AMCs.

Below, AMCs will be referred to as anti-rat or anti-human ( $\mathrm{Ab}) \mathrm{AMC}$ where $(\mathrm{Ab})$ is the surface antibody. For example, an AMC with an antibody against human vascular endothelial growth factor A would 
Table 1. Experimental conditions for in vitro and in vivo validation anti-hVEGF-A, anti-hTNF- $\alpha$, or anti-rIL-1 $\beta$ AMCs

\begin{tabular}{|c|c|c|c|c|c|c|c|c|c|c|}
\hline Condition set & $\begin{array}{c}\text { Experiment } \\
\text { or variable(s) } \\
\text { studied }\end{array}$ & $\begin{array}{l}\text { Surface } \\
\text { antibody }\end{array}$ & Length (mm) & I.D. (mm) & $\begin{array}{c}\text { Surface area } \\
\left(\mathrm{mm}^{2}\right)\end{array}$ & Aspect ratio ${ }^{A}$ & $\begin{array}{l}\text { PEG MW } \\
\text { (kDa) }\end{array}$ & $\begin{array}{l}\text { Ab conc. } \\
(\mu \mathrm{M})^{\mathrm{B}}\end{array}$ & $\begin{array}{c}\text { Flow } \\
\text { (ml/min) }\end{array}$ & pH \\
\hline \multicolumn{11}{|c|}{ Starting conditions } \\
\hline 1 & $\begin{array}{l}\text { rhVEGF-A } \\
\text { or rhTNF- } \alpha \\
\text { elimination } \\
\text { from BSA }\end{array}$ & $\begin{array}{c}\text { anti- } \\
\text { hVEGF-A or } \\
\text { anti-hTNF- } \alpha\end{array}$ & 222 & 3.2 & 2,251 & 70 & 10 & 3.4 & 40 & 7.4 \\
\hline 2 & $\begin{array}{l}\text { Blood (and } \\
\text { BSA for } \\
\text { comparison) }\end{array}$ & $\begin{array}{c}\text { anti- } \\
\text { hVEGF-A or } \\
\text { anti-hTNF- } \alpha\end{array}$ & 222 & 3.2 & 2,251 & 70 & 10 & 3.4 & 20 & $\begin{array}{l}\text { BSA 7.4; } \\
\text { blood not } \\
\text { measured }\end{array}$ \\
\hline \multicolumn{11}{|c|}{ Variables that determine AMC performance } \\
\hline 3 & $\begin{array}{c}\text { Flow rate } \\
\text { through } \\
\text { AMCs }\end{array}$ & anti-hTNF- $\alpha$ & 222 & 3.2 & 2,251 & 70 & 10 & 3.4 & $10-40$ & 7.4 \\
\hline 5 & Aspect ratio & anti-hTNF- $\alpha$ & 111-445 & $1.6-6.4$ & 2,217 & $18-280$ & 10 & 3.4 & 20 & 7.4 \\
\hline 6 & $\begin{array}{l}\mathrm{pH} \text { of } \\
\text { circulating } \\
\text { fluid }\end{array}$ & anti-hTNF- $\alpha$ & 886 & 1.6 & 4,458 & 554 & 10 & 3.4 & 20 & $6.8-7.6$ \\
\hline 7 & $\begin{array}{l}\text { MW of PEG } \\
\text { spacer }\end{array}$ & anti-hTNF- $\alpha$ & 886 & 1.6 & 4,458 & 554 & 3 or 10 & 3.4 or 6.7 & 20 & 7.4 \\
\hline 8 & $\begin{array}{c}\text { AMC surface } \\
\text { area }\end{array}$ & anti-hTNF- $\alpha$ & 150-886 & $0.8-3.2$ & $377-4,458$ & $47-554$ & 10 & 3.4 & 20 & 7.4 \\
\hline \multicolumn{11}{|c|}{ In vivo experiments } \\
\hline 9 & $\begin{array}{c}\text { IL-1 } \\
\text { elimination } \\
\text { in vivo }\end{array}$ & $\begin{array}{c}\text { Treatment: } \\
\text { anti-rIL-1 } \\
\text { anti- } \\
\text { hVEGF-A }\end{array}$ & 886 & 1.6 & 4,458 & 554 & 10 & 3.4 & $3.3 \pm 0.3$ & $6.8-7.2$ \\
\hline
\end{tabular}

${ }^{A}$ Aspect ratio $=A M C$ length/inner diameter. ${ }^{B} \mathrm{Ab}$ conc. = antibody concentration during conjugation. VEGF-A, vascular endothelial growth factor $A ;$ TNF- $\alpha$, tumor necrosis factor $\alpha$; IL-1 $\beta$, interleukin $1 \beta$; I.D., inner diameter; infliximab, monoclonal antibody against TNF- $\alpha$; PEG MW, poly(ethylene glycol) molecular weight; AMC, antibody-modified conduit.

be called anti-hVEGF-A AMC. The provenance of cytokines is denoted by $\mathrm{h}$ for human, $\mathrm{r}$ for rat, and $\mathrm{rh}$ for recombinant human. For example, recombinant human VEGF-A is rhVEGF-A. In the case of rat interleukin $1 \beta$ (rIL-1 $\beta$ ), both the recombinant and endogenous forms were studied (see section entitled Selective cytokine filtration by AMCs in vivo below). Antibodies against rIL-1 $\beta$ bind both the endogenous and recombinant forms and so the AMC and the cytokine are called anti-rIL-1 $\beta$ AMC and anti-rIL-1 $\beta$, respectively, without distinguishing between the recombinant and endogenous forms.

Cytokine elimination and mitigation of nonspecific binding. Cytokine filtration was assessed in vitro in an apparatus (Figure 1C) where solutions of cytokines, all in 5\% (w/v) BSA in PBS (pH 7.4) unless otherwise specified, were circulated through an AMC, and their concentration was measured over time in the reservoir. Cytokine elimination half-life $\left(\mathrm{T}_{1 / 2}\right)$ values were derived from one-phase, exponential decay curves fitted to plots of cytokine concentration over time (Supplemental Figure 1.2). Capacity (the amount of cytokine a given AMC can clear) was determined by circulating cytokine solutions through AMCs until cytokine removal ceased (i.e., the AMCs were saturated) and then measuring the total amount of cytokine eliminated from circulation. Initial AMC parameters (Table 1, condition 1) were chosen based on anticipated conditions in in vivo experiments. The sizes of the PEG spacer and the quantity of antibody were based on the literature on antibody-based biosensors (22).

When solutions containing 2,600 $\pm 600 \mathrm{pg} / \mathrm{ml} \mathrm{rhVEGF}-\mathrm{A}$ or $1,600 \pm 140 \mathrm{pg} / \mathrm{ml} \mathrm{rhTNF}-\alpha$ were circulated through anti-hVEGF-A AMCs (condition 1 in Table 1), rhVEGF-A was completely eliminated within approximately 1 hour (Figure $2 \mathrm{~A}$ ). The same circuit depleted rhTNF- $\alpha$ by $23.4 \% \pm 15.2 \%$ after 4 

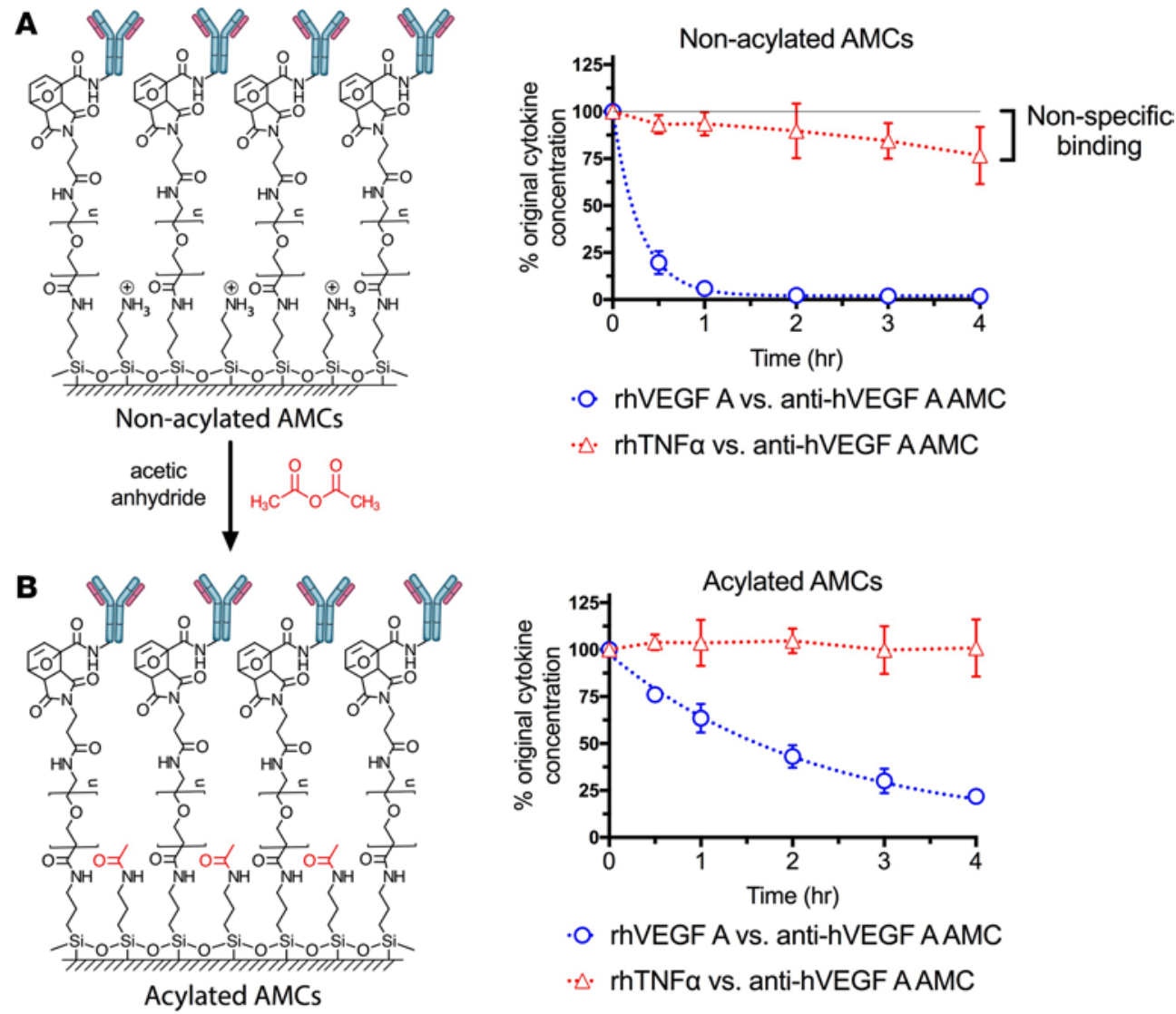

Figure 2. Elimination of nonspecific binding by passivation (acylation) with acetic anhydride. In both panels, the left side shows a schematic of the AMC surface, and the right side the related elimination kinetics. (A) Elimination of recombinant human VEGF-A (rhVEGF-A) and rhTNF- $\alpha$ from unpassivated anti-hVEGF-A AMCs. (B) The same experiment as in panel A with passivated anti-hVEGF-A AMCs. All data are means \pm SD. $n=4$ for each group. All cytokine solutions were in $5 \%(\mathrm{w} / \mathrm{v}) \mathrm{BSA}$ and circulated at $40 \mathrm{ml} / \mathrm{min}$.

hours, suggesting some nonspecific binding. Nonspecific binding was shown to be mediated by unreacted amine moieties on APTMS (Supplemental Note 2) and was preventable by treating the conduit with acetic anhydride to acylate unreacted amine moieties before the antibody addition step (Figure $2 \mathrm{~B}$ and Supplemental Note 3). Acylation slightly reduced cytokine clearance by AMCs (See Supplemental Note 3). Nonetheless, all subsequent AMCs were acylated with acetic anhydride prior to antibody conjugation (Figure 1B) to ensure that cytokine elimination was highly selective.

Filtration of human blood. AMCs were characterized with cytokine solutions in PBS containing 5\% $(\mathrm{w} / \mathrm{v}) \mathrm{BSA}$ in the preceding experiments. However, AMCs must be able to eliminate cytokines from circulating blood, which is a more complex medium than PBS containing BSA.

To test whether AMCs could mitigate cytokine levels in blood, we mimicked the clinical situation where cytokine levels are already elevated at initiation of treatment. Heparinized human whole blood with rhTNF- $\alpha$ $(2,860 \pm 170 \mathrm{pg} / \mathrm{ml})$ was circulated through anti-hTNF- $\alpha$ AMCs (Table 1, condition 2, Supplemental Note 4) (Supplemental Table 1). Flow rates through AMCs were selected to approximate target extracorporeal blood flow rates $(10-40 \mathrm{ml} / \mathrm{min})$ in eventual in vivo experiments; we did not know what flow rates within that range would be attained in vivo, and so we chose $20 \mathrm{ml} / \mathrm{min}$. rhTNF- $\alpha$ elimination from blood by AMCs was then measured to determine rhTNF- $\alpha \mathrm{T}_{1 / 2}$ and compared to rhTNF- $\alpha$ elimination when $5 \%(\mathrm{w} / \mathrm{v})$ BSA was the circulating fluid (starting rhTNF- $\alpha 1,930 \pm 270 \mathrm{pg} / \mathrm{ml}$ ) (Supplemental Note 4); this comparison was made to determine if $5 \%(\mathrm{w} / \mathrm{v}) \mathrm{BSA}$ could be used as a suitable surrogate for human blood during subsequent in vitro experiments. The starting rhTNF- $\alpha$ concentrations in both solutions were approximately 10 -fold greater than those observed in humans during sepsis $(23,24)$. The $\mathrm{T}_{1 / 2}$ in blood and $5 \%(\mathrm{w} / \mathrm{v})$ BSA were similar $(P=0.55$, unpaired $t$ test). Since the rates of rhTNF- $\alpha$ elimination from $5 \%(\mathrm{w} / \mathrm{v}) \mathrm{BSA}$ and whole blood were similar, experiments to characterize AMC performance (following section) were conducted in 5\% (w/v) BSA. 


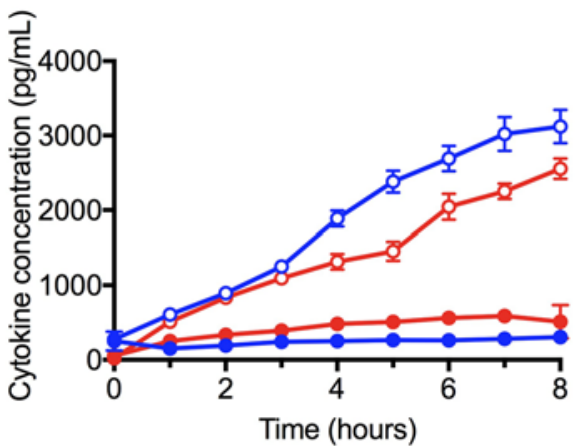

\author{
rhVEGF A vs. anti-hVEGF AAMC \\ rhVEGF A vs. anti-hTNF $\alpha$ AMC \\ rhTNF $\alpha$ vs. anti-hTNF $\alpha$ AMC \\ rhTNFa vs. anti-hVEGF A AMC
}

Figure 3. Elimination of recombinant human TNF- $\alpha$ (rhTNF- $\alpha$ ) and rhVEGF-A continuously infused into human whole blood circulating through antibody-modified conduits (AMCs). All data are means \pm SD. $n=4$ for each group.

Next, we mimicked the clinical situation where patients continuously produce cytokines (Figure 3) by continuously infusing rhVEGF-A together with rhTNF- $\alpha$ into heparinized human whole blood so that the circulating concentrations of both cytokines increased at approximately $20 \mathrm{pg} / \mathrm{ml} / \mathrm{h}$ for VEGF-A and 60 $\mathrm{pg} / \mathrm{ml} / \mathrm{h}$ for TNF- $\alpha$, rates in excess of what is reported in animal models of sepsis (25). Blood circulated through anti-hTNF- $\alpha$ AMCs (Table 1, condition 2; same AMC properties as those used in the preceding paragraph) prevented the increase in blood rhTNF- $\alpha$ levels. Similarly, anti-hVEGF-A AMCs (Table 1, condition 2; same AMCs as those used in Figure 2 and shown in Supplemental Table 1 except that flow rate was $20 \mathrm{ml} / \mathrm{min}$ here) prevented rhVEGF-A concentrations from increasing. Neither AMC was able to prevent a rise in the concentration of the cytokine to which it did not have a specific antibody.

Variables that determine AMC performance. We used anti-hTNF- $\alpha$ AMCs to study variables that determine AMC performance in eliminating rhTNF- $\alpha$ (Table 1): flow rate through AMCs, concentration of antibody used during conjugation, AMC aspect ratio (length/inner diameter), $\mathrm{pH}$ of circulating fluid, molecular weight of PEG spacer, and AMC surface area. TNF- $\alpha$ was used as the model cytokine because it is involved in sepsis pathogenesis and because historically it has been difficult to eliminate from the circulation by nonselective extracorporeal blood purification (EBP) methods (26-28). Solutions of rhTNF- $\alpha$ were circulated through anti-hTNF- $\alpha$ conduits and rhTNF- $\alpha$ elimination was measured (Supplemental Figure 1.2) to determine $T_{1 / 2}$ values and/or capacity for rhTNF- $\alpha$.

Flow rate through AMCs. In septic patients, middle-molecular-weight proteins (including cytokines) are eliminated more rapidly if a greater fraction of a patient's cardiac output is processed (29) (i.e., a greater fraction of a patient's cardiac output is processed). To determine the flow rate through AMCs on cytokine elimination, rhTNF- $\alpha$ solutions were circulated through anti-hTNF- $\alpha$ AMCs at various flow rates (Table 1 , condition 3 , which is condition 1 with variable flow rates) and rhTNF- $\alpha$ elimination was measured (Supplemental Figure 1.2A) to determine rhTNF- $\alpha \mathrm{T}_{1 / 2}$ values (Figure $4 \mathrm{~A}$ and Supplemental Table 1). $\mathrm{T}_{1 / 2}$ decreased by $34 \%$ when flow increased from $10 \mathrm{ml} / \mathrm{min}$ to $20 \mathrm{ml} / \mathrm{min}$ [1-way ANOVA, $F(3,14)=5.7, P=0.01]$ but did not decrease with further increases in flow. Since the maximum rate of TNF- $\alpha$ elimination occurred at or above $20 \mathrm{ml} / \mathrm{min}$, all subsequent AMC characterizations were performed with flow rates of $20 \mathrm{ml} / \mathrm{min}$.

Concentration of antibody used during conjugation. To determine the effect of antibody loading in the AMC that would result in the most rapid cytokine elimination, AMCs were prepared with varying concentrations of anti-hTNF- $\alpha$ antibody in the antibody conjugation step. Solutions of rhTNF- $\alpha$ were circulated through those AMCs (Table 1, condition 4 which is condition 1 with a flow rate of $20 \mathrm{ml} / \mathrm{min}$ ) and rhTNF- $\alpha$ elimination was measured (Supplemental Figure 1.2B) to determine $\mathrm{T}_{1 / 2}$ values (Figure $4 \mathrm{~B}$ and Supplemental Table 2). Between $0.7 \mu \mathrm{M}$ and $6.7 \mu \mathrm{M}$ antibody, $\mathrm{T}_{1 / 2}$ decreased $3.4 \pm 0.8$-fold with increasing antibody concentration [1-way ANOVA, $F(5,18)=41, P<0.0001$ ]. Antibody concentrations greater than $6.7 \mu \mathrm{M}$ did not further reduce $\mathrm{T}_{1 / 2}$.

Aspect ratio (length/inner diameter). To determine if the AMC aspect ratio influenced the rate of cytokine elimination, the length and inner diameter of AMCs were varied while maintaining a constant surface area (Table 1, condition 5). Solutions of rhTNF- $\alpha$ were circulated through AMCs and rhTNF- $\alpha$ elimination was measured (Supplemental Figure 1.2C) to determine $\mathrm{T}_{1 / 2}$ values (Figure $4 \mathrm{C}$ and Supplemental Table 3). Aspect 
A

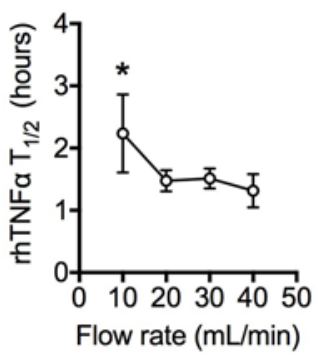

D

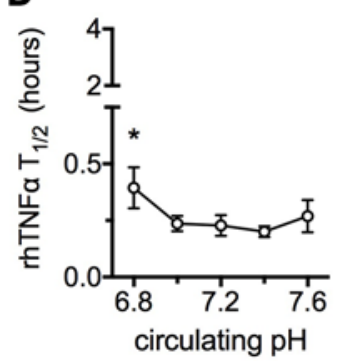

G

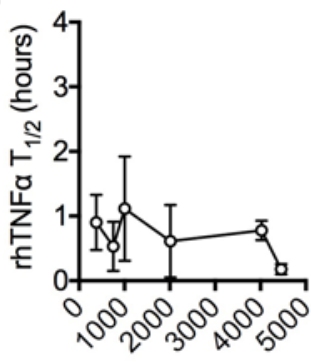

Surface area $\left(\mathrm{mm}^{2}\right)$
B

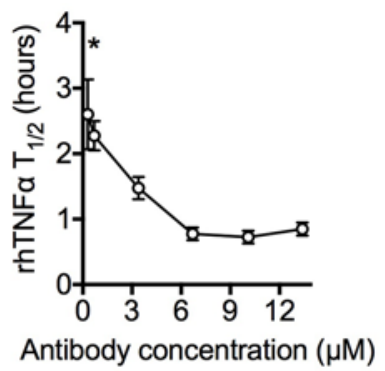

E

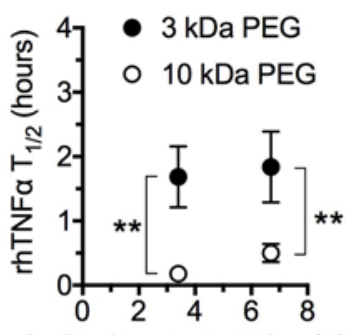

Antibody concentration $(\mu \mathrm{M})$
C

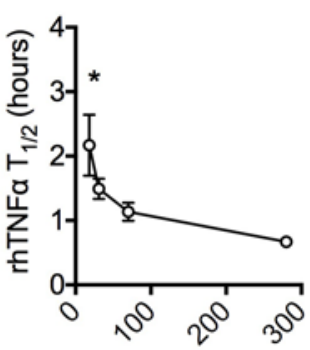

Aspect ratio

(length/inner diameter)

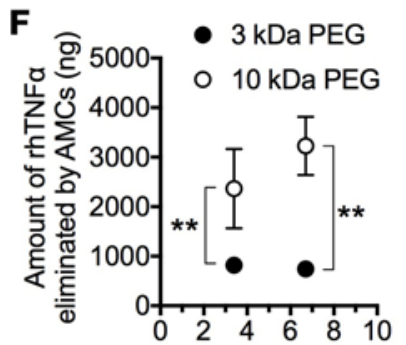

Antibody concentration $(\mu \mathrm{M})$
H

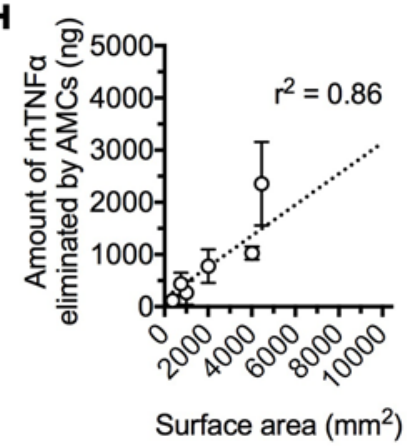

Figure 4. Effect of fluid characteristics and antibody-modified conduit (AMC) properties on the rate of recombinant human TNF- $\alpha$ (rhTNF- $\alpha$ ) elimination half-life ( $\left.\mathbf{T}_{1 / 2}\right)$ and/or amount of rhTNF- $\alpha$ captured by AMCs (i.e., capacity). (A) Flow rate through AMCs $(n=5$ for $10 \mathrm{ml} / \mathrm{min}, n=4 \mathrm{for} 20$ and 30 $\mathrm{ml} / \mathrm{min}, n=6$ for $40 \mathrm{ml} / \mathrm{min}$ ). (B) Concentration of anti-hTNF- $\alpha$ antibody used during conjugation ( $n=4)$. (C) Aspect ratio (length/inner diameter) ( $n=4)$. (D) $\mathrm{pH}$ of circulating fluid $(n=4)$. (E and F) Poly(ethylene glycol) (PEG) molecular weight $(n=8$ for AMCs prepared with $10-\mathrm{kDa}$ PEG/3.4 $\mu \mathrm{M}$ antibody; $n=$ 4 for all other groups). ( $(\mathbf{G}$ and $\mathbf{H})$ Surface area $(n=4)$. Experiments for $\mathbf{A}$ and $\mathbf{B}$ were conducted with small-aspect-ratio $(=70)$ AMCs and experiments for D-H were conducted with large-aspect-ratio $(=554)$ AMCs. ${ }^{*} P<0.05$ by 1 -way ANOVA. ${ }^{* *} P<0.0001$ for comparisons between PEG molecular weight and between antibody concentration by 2-way ANOVA with Bonferroni's post hoc correction. Data are presented as means \pm SD.

ratio had a marked effect on $\mathrm{T}_{1 / 2}$. For example, AMCs with an aspect ratio of 280 (i.e., long with small inner diameter) yielded $\mathrm{T}_{1 / 2}$ values approximately 3 -fold lower than AMCs with an aspect ratio of 18 (i.e., short with large inner diameter) [1-way ANOVA, $F(2,8)=13, P=0.003$ ]. Consequently, all subsequent AMCs were prepared with aspect ratios of at least 280 (even larger aspect ratio AMCs were utilized in subsequent experiments as a result of increasing AMC length to increase surface area; those AMCs are not presented here because of variable surface area). Aspect ratios for all experiments are reported in Table 1.

$\mathrm{pH}$ of circulating fluid. Patients with sepsis experience fluctuations in blood $\mathrm{pH}$. To determine whether $\mathrm{pH}$ would affect cytokine elimination, solutions of $\mathrm{rhTNF}-\alpha$ at a range of physiologically relevant $\mathrm{pH}$ values (6.8, 7.0, 7.2, 7.4, and 7.6) were circulated through anti-hTNF- $\alpha$ AMCs and rhTNF- $\alpha$ elimination was measured (Supplemental Figure 1.2D) and $\mathrm{T}_{1 / 2}$ computed (Figure $4 \mathrm{D}$ and Supplemental Table 4). AMC design parameters developed above were used for these experiments (aspect ratio 554, 10-kDa PEG, $3.4 \mu \mathrm{M}$ rhTNF- $\alpha$; Table 1 , condition 6). The rate of rhTNF- $\alpha$ elimination was approximately 2-fold slower (larger $\mathrm{T}_{1 / 2}$ ) at $\mathrm{pH} 6.8$, but was not affected by changes in $\mathrm{pH}$ between 7.0 and 7.6 [1-way ANOVA, $F(2,9)=9.3, P=0.007$ ].

Molecular weight of PEG spacer. Spacer length is an important determinant of antibody-ligand binding efficiency in other contexts $(22,30)$. To determine if PEG spacer length influenced cytokine elimination, AMCs were produced with $3-\mathrm{kDa}$ or $10-\mathrm{kDa}$ PEG spacers, at 2 concentrations of anti-hTNF- $\alpha$ antibody. (We studied 
A

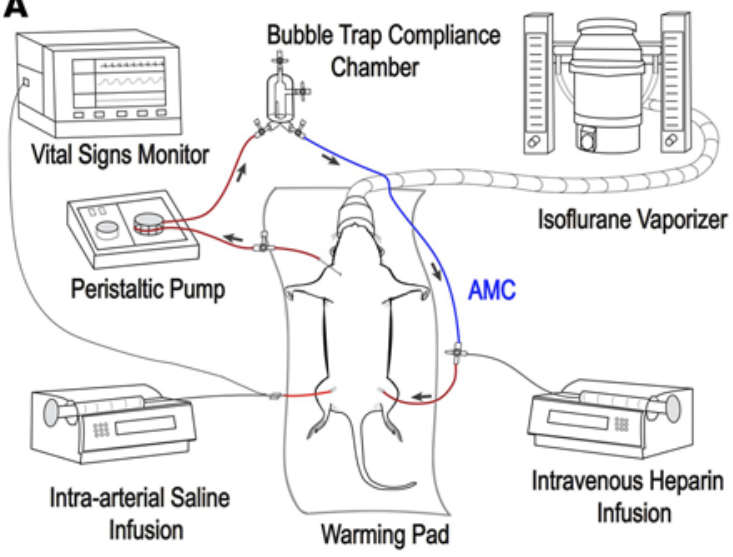

C
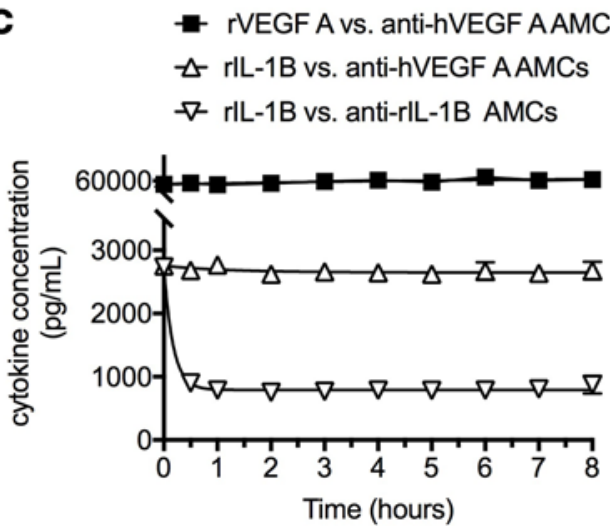

B

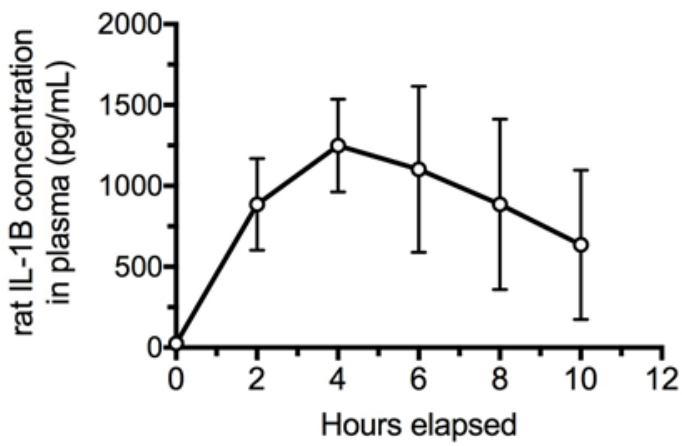

D

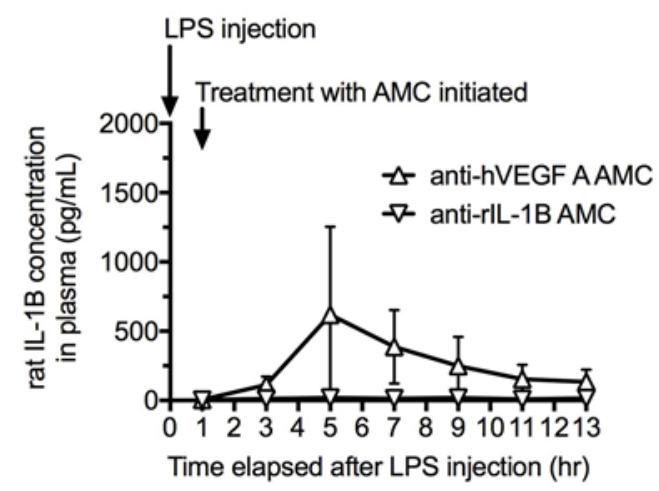

Figure 5. Cytokine clearance by antibody-modified conduits (AMCs) after lipopolysaccharide (LPS) administration (a model of hypercytokinemia) in vivo in rats. (A) Schematic of extracorporeal circulation through AMCs in rats; the AMC component of the circuit is blue and arrows represent direction of blood flow. (B) Time courses of plasma IL-1 $\beta$ concentration in rats following intravenous injection of LPS $(n=4)$. (C) Time courses of recombinant rat IL-1 $\beta$ (rIL-1 1 ) or recombinant rat VEGF-A (rVECF-A) concentrations in vitro during circulation through anti-rIL-1 $\beta$ or anti-human VEGF-A (anti-hVEGF-A) AMCs. (D) Concentration of plasma IL-1 $\beta$ in rats injected with LPS (first arrow) and then treated with anti-rIL-1 $\beta$ or anti-hVEGF-A AMCs (second arrow). Data are presented as means \pm SD of $n$ observations. $n=4$ for in vitro experiments. $n=6$ for anti-rlL-1 $\beta$ AMCs. $n=4$ for anti-hVEGF-A AMCs.

2 antibody concentrations because of the possibility that PEG spacer size could influence the optimal antibody concentration needed for substrate binding, see ref. 22; in preceding experiments 3.4 and $6.7 \mu \mathrm{M}$ encompassed the point at which increasing antibody concentration failed to yield further reductions in $\mathrm{T}_{1 / 2}$ [Figure $4 \mathrm{~B}$ ], and so those 2 concentrations were studied here). Solutions of rhTNF- $\alpha$ were circulated through large-aspect-ratio (= 554) AMCs (Table 1, condition 7) and rhTNF- $\alpha$ elimination was measured (Supplemental Figure 1.2, E and F) to determine $\mathrm{T}_{1 / 2}$ values and capacity. At both concentrations of anti-hTNF- $\alpha$ antibody, AMCs synthesized with 10-kDa PEG yielded more rapid rhTNF- $\alpha$ clearance (i.e., smaller $\mathrm{T}_{1 / 2}$ values) (Figure $4 \mathrm{E}$ ) and greater amounts of rhTNF- $\alpha$ were eliminated (capacity) (Figure $4 \mathrm{~F}$ ) than with $3-\mathrm{kDa}$ PEG. At either PEG molecular weight, antibody concentration did not influence $\mathrm{T}_{1 / 2}$ (Figure $4 \mathrm{E}$ and Supplemental Table 5) or capacity (Figure $4 \mathrm{~F}$ and Supplemental Table 5) for these large-aspect-ratio AMCs (smallest $P=0.08$ for both comparisons, 2-way ANOVA with Bonferroni's post hoc correction), unlike the effect in small-aspect-ratio AMCs (Figure 4B). Since all subsequent $\mathrm{AMCs}$ had large aspect ratios, they were prepared with $10-\mathrm{kDa}$ PEG and $3.4 \mu \mathrm{M}$ antibody solutions.

Conduit surface area. Solutions of rhTNF- $\alpha$ were circulated through circuits containing anti-hTNF- $\alpha$ AMCs that varied by surface area (Table 1, condition 8) and rhTNF- $\alpha$ elimination was measured (Supplemental Figure $1.2 \mathrm{G}$ ) to determine $\mathrm{T}_{1 / 2}$ values and capacity. The $\mathrm{T}_{1 / 2}$ for rhTNF- $\alpha$ was not influenced by AMC surface area $[F(4,13)=0.7, P=0.6,1$-way ANOVA] (Figure 4G). However, post-hoc comparison of individual data points revealed that when surface area increased from $4,021 \mathrm{~mm}^{2}$ to $4,458 \mathrm{~mm}^{2}, \mathrm{~T}_{1 / 2}$ was significantly reduced ( $P=0.004$, unpaired $t$ test). A strong linear correlation between surface area and capacity was observed $\left[F(1,6)=38.5, P=0.001\right.$ with $R^{2}$ of 0.87$]$ (Figure $4 \mathrm{H}$ ). Because the maximum 
antibody concentration (i.e., the concentration above which capacity is no longer increased; Figure 4F) was used in these AMCs, the only way to augment $\mathrm{T}_{1 / 2}$ and capacity further was with additional surface area.

Selective cytokine filtration by AMCs in vivo. We developed an animal model of veno-venous extracorporeal circulation (Figure 5A; see Methods for detailed description of model) in rats rendered hypercytokinemic by intravenous LPS injection. Pilot LPS-dose-finding studies (Supplemental Note 5) demonstrated that elevations in plasma rTNF- $\alpha$ occurred early and were not sustained. Since plasma levels of rIL-1 $\beta$ were elevated over the course of the experiment (Figure 5B), we selected it for mitigation by AMCs. We calculated the AUC in Figure 5B to determine the total mass of rIL-1 $\beta$ in blood during an episode of LPS-induced hypercytokinemia (see Supplemental Note 6 for detailed calculations) to be $31.1 \pm 14.1 \mathrm{ng}$; this mass was used as the minimum capacity required of anti-rIL-1 $\beta$ AMCs in this animal model.

Anti-rIL-1 $\beta$ AMCs (Table 1, condition 9) were prepared and then characterized in vitro with solutions of $\mathrm{rIL}-1 \beta$ in $5 \%(\mathrm{w} / \mathrm{v})$ BSA (Figure $5 \mathrm{C} ; \mathrm{T}_{1 / 2}=0.1 \pm 0.02$ hours, capacity $=38.8 \mathrm{ng} \pm 1.0 \mathrm{ng}, n=4$ ). AntihVEGF-A AMCs produced by the same procedure did not eliminate rIL-1 $\beta$ or rVEGF-A (Figure $5 \mathrm{C}$ ) and so were used as control AMCs that would not bind rIL-1 $\beta$ in vivo.

Of note, anti-rIL-1 $\beta$ AMCs were characterized in vitro using flow rates of $20 \mathrm{ml} / \mathrm{min}$ (approximately $21 \%$ of rat cardiac output at the doses of isoflurane used here; see ref. 31) based on the assumption that those conditions would accurately approximate in vivo conditions. However, the maximum flow rate for whole blood that was attainable with the in vivo pump and circuit system was $3.3 \pm 0.3 \mathrm{ml} / \mathrm{min}(3 \%-4 \%$ of cardiac output; see Methods for details of how flow was measured). Those flow rates as a percentage of cardiac output are comparable to those used in humans receiving continuous renal replacement therapy (32).

Animals were injected with $17.5 \mathrm{mg} / \mathrm{kg}$ intravenous LPS and randomized to undergo extracorporeal circulation with either anti-rIL-1 $\beta$ AMCs $(n=6)$ or anti-hVEGF-A AMCs $(n=4)$ (Figure 5D). rIL-1 $\beta$ concentrations after LPS administration but immediately prior to initiating extracorporeal circulation were similar in both groups $(4.2 \pm 3.0 \mathrm{pg} / \mathrm{ml}$ and $5.6 \pm 5.3 \mathrm{pg} / \mathrm{ml}$ for rats treated with anti-rIL-1 $\beta$ AMCs and antihVEGF-A AMCs, respectively; $P=0.6$, unpaired $t$ test). In rats treated with anti-hVEGF-A AMCs, plasma rIL-1 $\beta$ concentrations rose to a peak of $642 \pm 619 \mathrm{pg} / \mathrm{ml}$ and remained elevated throughout the duration of the experiment (AUC $3.1 \pm 2.4 \mathrm{ng} \cdot \mathrm{hr} / \mathrm{ml}$ ). In rats treated with anti-rIL-1 $\beta$ AMCs, peak plasma rIL-1 $\beta$ concentrations never rose above $28.2 \pm 14.1 \mathrm{pg} / \mathrm{ml}$ (AUC $0.1 \pm 0.02 \mathrm{ng} \cdot \mathrm{hr} / \mathrm{ml}$ ). The difference between AUCs was statistically significant ( $P=0.01$, unpaired $t$ test). The AUCs for the time courses of blood levels of rIL-1 $\beta$ (i.e., the total mass of rIL-1 $\beta$ eliminated by anti-rIL-1 $\beta$ AMCs) was $6.5 \pm 5.5 \mathrm{ng}$, which was approximately $16 \%-17 \%$ of total anti-rIL-1 $\beta$ AMC capacity (see Supplemental Note 7 for detailed calculations). The results demonstrated that anti-rIL-1 $\beta$ AMCs successfully eliminated rIL-1 $\beta$ from the circulation.

\section{Discussion}

This study developed highly selective blood-filtering devices by tethering anti-cytokine antibodies to extracorporeal surfaces that contact circulating blood (Figure 1B). After validating selective filtration with AMCs (Figure 2), we demonstrated that AMCs could clear circulating cytokines from human blood (Supplemental Figure 4) and maintain them in reduced states in the face of ongoing production (Figure 3). Using TNF- $\alpha$ as the model cytokine, we demonstrated cytokine filtration over a range of physiologically relevant $\mathrm{pH}$ values (acidosis is a common feature of critically ill patients; see ref. 33) and characterized variables that determine AMC performance (Figure 4). Finally, we validated the concept of selective cytokine elimination in rats with elevated circulating cytokines (Figure 5).

We chose to characterize AMCs in vitro using anti-hTNF- $\alpha$ AMCs to eliminate rhTNF- $\alpha$ as the model cytokine because historically TNF- $\alpha$ has been difficult to eliminate by nonselective EBP methods (26-28). Successful AMC characterization with the most difficult to eliminate cytokine (TNF- $\alpha$ ) portends successful elimination of other cytokines less resistant to elimination by EBP. For example, the rate of rIL-1 $\beta$ elimination by anti-rIL-1 $\beta$ AMCs $\left(\mathrm{T}_{1 / 2}=0.1 \pm 0.02\right)$ was similar to the rate of rhTNF- $\alpha$ elimination by anti-hTNF- $\alpha$ AMCs $\left(\mathrm{T}_{1 / 2}=0.2 \pm 0.1\right)(P=0.19$, Student's 2-tailed $t$ test). However, rTNF- $\alpha$ expression in response to LPS injection was too transientto study TNFA elimination by

AMCs for prolonged periods (Supplemental Note 5). Therefore, we chose to target rIL-1 $\beta$ for elimination (rather than TNF- $\alpha$ ), which remained persistently elevated after LPS injection (Figure 5B).

In developing the animal model, we found that the flow rates achieved in vivo were markedly less than anticipated (and therefore less than the flow rates studied in vitro), which may have reduced the rate of rIL$1 \beta$ elimination, based on the observation that flow rate exerts some influence on the rate of cytokine elimi- 
nation (Figure 4A). As a consequence, a smaller fraction of rat cardiac output ( $3 \%-4 \%$; not accounting for any potential recirculation into the circuit) was circulated through AMCs at any given moment, reducing the fraction of circulating blood volume processed by AMCs. However, the flow rates studied in vivo were comparable to those used for continuous renal replacement therapy in humans (32) and was sufficient to prevent rIL-1 $\beta$ from becoming elevated (Figure 5D).

A major objective of this study was the demonstration of selective elimination of a single cytokine in vivo under conditions where multiple cytokines are elevated simultaneously. To accomplish this, we used intravenous LPS injection, which caused rapid elevation of multiple cytokines that the AMCs could be tested against in vivo. The study was not designed to detect longer-term physiological or survival differences. Ultimately, assessing the impact of AMCs on physiological variables and long-term survival may require a more clinically relevant model (e.g., cecal ligation and puncture as a model of sepsis) (34) with supportive therapies over a longer time, and AMC selection guided by host response. The technology already exists for the rapid (2 hours), simultaneous measurement of multiple cytokines relevant to sepsis (24) and even faster with emerging technologies ( $\sim 40$ minutes) (17).

All rats underwent treatment with AMCs for 12 hours without implementation of supportive measures such as mechanical ventilation to regulate $\mathrm{pH}$, dextrose to prevent hypoglycemia, and vasoactive medications to reverse hypotension. Consequently, rats in both treatment groups developed acidemia, hypoglycemia, and hypotension (Supplemental Figure 6). All surviving rats were sacrificed (50\% of rats in the anti-hVEGF-A AMC group and 16\% in the anti-IL-1 $\beta$ AMC group) at the predetermined experimental endpoint of 13 hours after LPS injection. Since survival and duration of survival were not due only to disease and treatment, but also experimental protocol, no survival differences were observed (median survival 12.67 hours (interquartile range [IQR] 11.4-13 for rats treated with anti-hVEGF-A AMCs vs. 10.22 [IQR 7.1-12.1] for rats treated with anti-rIL-1 $\beta$ AMCs; $P=0.10$, Mann-Whitney $U$ test).

AMCs are a platform technology that could in theory be used to treat any disease characterized by pathogenic circulating factor(s), for example plasma free myoglobin or hemoglobin, toxins (e.g., endotoxin, shiga toxin) or immune complexes. We chose hypercytokinemia as the model condition and cytokines as the initial targets for several reasons. First, cytokines play a prominent role in the pathogenesis of many diseases in which immune dysregulation is present and their modulation may be clinically important. Second, many clinically relevant anti-cytokine antibodies from which to construct a diverse library of AMCs already exist. With AMCs it would be possible to eliminate multiple specific cytokines simultaneously. As used here, each AMC filters a single cytokine, although AMCs could be made to filter more than one cytokine via incorporation of additional antibodies against other cytokines (Supplemental Note 8); alternatively, more than one cytokine-specific AMC could be used simultaneously. AMC combinations could be chosen to eliminate multiple, specific, deleterious cytokines as dictated by highly variable host cytokine expression. To the best of our knowledge, no prior strategy could enable both molecular and temporal specificity in modulating multiple cytokines.

AMCs could potentially be useful in treating the dysregulated immune response in sepsis, which involves highly variable and dynamic cytokine expression (10-12). Patterns of cytokine expression have prognostic significance. For example, early expression of inflammatory cytokines is associated with hypotension and multiple organ failure $(23,24,35)$, sustained antiinflammatory cytokine expression is associated with late mortality $(11,35,36)$, and mortality is greatest when both inflammatory and antiinflammatory cytokines are elevated (37). The timing and degree of cytokine expression, as well as which cytokines are expressed, is highly variable between individuals (38), and even in the same patient over time (11). Strategies to reduce cytokines have included nonspecific extracorporeal cytokine removal (2) and targeted neutralization of inflammatory cytokines with monoclonal antibodies (39-43), which were potentially limited by either lack of molecular or temporal specificity. AMCs could in theory be used to eliminate only cytokines that are deleterious at a given time (either proinflammatory or antiinflammatory, depending on clinical circumstances), without removing other factors best left in the circulation, and in a manner that matches changing host cytokine expression.

It is difficult to accurately predict the quantities of cytokine that would have to be eliminated from humans since the precise quantity of cytokine production is not known. However, using TNF- $\alpha$ expression during sepsis as an example, if one knows the plasma cytokine concentration (approximately 300 $\mathrm{pg} / \mathrm{ml}$ in patients who died from sepsis) (24) and circulating blood volume (2.89-9.65 1) (44), it is possible to determine the total mass of a given cytokine in the vascular compartment at any one time (peak mass 867-2,895 ng for TNF- $\alpha$ in this example). Although this does not account for ongoing production, clearance, or TNF- $\alpha$ in other tissue compartments, it serves as a clinically relevant quantity to define a 
minimum AMC capacity necessary for humans. The volumes of cytokine solution used in this study (20 $\mathrm{ml}$ ) were far less (145-483 times) than the blood volume of humans. However, by introducing cytokine concentrations as much as 1,280 \pm 90 times greater than what is observed clinically (Supplemental Figure 1.2), we were able to challenge AMCs with total cytokine masses similar to what is seen in patients who died from sepsis (Figure $4 \mathrm{H}$ and Supplemental Table 5).

We identified upper limits to how much AMC capacity could be increased (Figure $4 \mathrm{~F}$ ) and $\mathrm{T}_{1 / 2}$ reduced (Figure 4, B and E) by using additional antibody, suggesting either surface saturation with antibodies or increasing steric hindrance with greater packing density of surface antibodies (45). We found that AMCs with large $(10 \mathrm{kDa})$ PEG spacers yielded smaller TNF- $\alpha \mathrm{T}_{1 / 2}$ values and greater capacity than AMCs with small $(3 \mathrm{kDa})$ PEG spacers (Figure 4, E and F). This was likely the result of reduced steric hindrance, which is consistent with the observation that larger spacers mitigate steric effects and enhance antigen capture in biosensors (22). However, an equally plausible explanation is that antibody conjugation to maleimide surfaces was more extensive in conduits with $10-\mathrm{kDa}$ spacers.

Cytokine concentrations appeared to decay exponentially over time (Figure 2, Figure 5C, Supplemental Figure 1.2, Supplemental Figure 2, Supplemental Figure 3, Supplemental Figure 4A, and Supplemental Figure 7). We derived a mathematical model to describe the rate of cytokine elimination based on first-order exponential decay kinetics (detailed derivation in Supplemental Note 9). The model accurately described cytokine elimination kinetics when compared to measured experimental data (Supplemental Figure 8), thus validating the methods used to quantify AMC performance.

EBP has been used to eliminate host inflammatory mediators, based on the principle that their removal will favorably modulate the immune derangements from sepsis or cardiopulmonary bypass. Multiple modalities have been examined including hemofiltration, plasma exchange, hemoperfusion alone, and hemoperfusion combined with either hemofiltration or plasma exchange (2). None improved survival. Of the EBP technologies designed to filter cytokines, none are selective. All eliminate pro- and antiinflammatory cytokines simultaneously as well as other entities best left in the circulation such as therapeutic drugs (6) and clotting factors (7). Recently, methods have been devised to render nonspecific hemofiltering sorbents semiselective via regulation of pore size through which target molecules pass, including polystyrene divinyl benzene (PDVB) copolymer beads and porous cellulose beads $(26,27,46)$. Such approaches restricted filtration to small and middle size proteins (typically less than $45 \mathrm{kDa}$ ), which include most cytokines and endotoxin. Both polymer systems depleted a wide range of inflammatory and antiinflammatory cytokines, except for TNF- $\alpha$, which was captured to a lesser extent due to pore size exclusion of the large TNF- $\alpha$ trimer (51 kDa) (26-28). For example, hemoperfusion with PDVB copolymer bead columns in human subjects with sepsis and acute lung injury reduced circulating blood levels of IL-6, IL-1ra, MCP-1, and IL-8 but not TNF- $\alpha$. Survival was not improved (47). In addition, semiselective sorbents also depleted triiodothyronine and cortisol (3), which play crucial roles in the stress response of patients with shock (48). By contrast, TNF- $\alpha$ elimination by AMCs is readily achievable (Figure 4) and AMCs can be designed to adjust how rapidly and how much TNF- $\alpha$ is eliminated from the circulation. And, given the highly selective nature of antibody-cytokine interactions (Figure 2C and Supplemental Figure 3), clinically important entities should not be eliminated from the circulation. (We eliminated all nonspecific binding by AMCs; Figure 2C and Supplemental Figure 3).

We developed AMCs to eliminate 3 different inflammatory cytokines (hTNF- $\alpha$, hVEGF-A, and rIL$1 \beta)$. However, AMCs would not be limited to inflammatory cytokines in clinical practice. For example, persistent IL-10 release inhibits clearance of primary infections and enhances susceptibility to secondary infections (11) (this is consistent with the observation that a high number of patients who die from sepsis were found have unresolved opportunistic infections; see refs. 49, 50). AMCs could then hypothetically be used to reverse IL-10-mediated immunosuppression through selective IL-10 elimination.

In summary, AMCs provide a flexible and highly selective blood-filtering platform to enable elimination of individual, harmful cytokines as they are expressed, without eliminating other cytokines best left in the circulation. This strategy is congruent with the emerging consensus that as the understanding of the dysregulated immune response to critical illness improves, personalized treatment strategies will be important (38).

\section{Methods}

Materials. PDMS tubing was purchased from Cole-Parmer Instrument Company. APTMS, BSA, 2-furoic acid (F2505), $N$-(3-dimethylaminopropyl)- $N$-ethylcarbodiimide hydrochloride (EDC), $N$-hydroxysuccinimide (NHS), 2-( $N$-morpholino)ethanesulfonic acid (MES), methanol, PBS, acetic anhydride, 2-mercaptoeth- 
anol, dichloromethane (DCM), and LPS were purchased from Sigma-Aldrich. Heterobifunctional PEG functionalized with an NHS ester on one terminus and a maleimide moiety on the other (NHS-PEG - MAL, where $\mathrm{n}$ is the molecular weight of the PEG molecule and was 3 or $10 \mathrm{kDa}$ ) was purchased from Rapp Polymere. Infliximab (Janssen Biotech, Inc.) and bevacizumab (Genentech, Inc.) were obtained from the Boston Children's Hospital (BCH) pharmacy. Anti-rIL-1 $\beta$ antibodies (catalog number 503504, clone number B122) were obtained from BioLegend. rhVEGF-A and rhTNF- $\alpha$ were obtained from R\&D Systems, Inc. Rat recombinant IL-1 $\beta$ was obtained from BioLegend. Enzyme-linked immunosorbent assays (ELISAs) were obtained from R\&D Systems, Inc. Human whole blood was obtained from Research Blood Components, LLC. NHS-fluorescein and 5-((2-(and-3)-S-(acetylmercapto) succinoyl) amino) (SAMSA) fluorescein were purchased from ThermoFisher Scientific. Rats were obtained from Charles River Laboratories, Inc.

AMC fabrication. Anti-cytokine antibodies were conjugated to luminal surfaces of PDMS conduits (Figure 1B). Surface plasma oxidation, followed by amino-silanization with APTMS, PEGylation with NHS-PEG ${ }_{n}$-MAL, and passivation of residual amines with acetic anhydride resulted in maleimide-functionalized surfaces. Antibody conjugation was accomplished by coupling furan-modified antibodies to the maleimide-functionalized surfaces. Three AMC prototypes were developed, one to filter hVEGF-A, a second to filter hTNF- $\alpha$, and a third to filter rIL-1 $\beta$.

Coupling of furan-NHS ester to antibodies. 2-Furoic acid (0.5 g, $4.1 \mathrm{mmol})$, EDC (2.4 g, $12.3 \mathrm{mmol})$, and NHS (1.4 g, $12.3 \mathrm{mmol})$ were added in a 1:3:3 molar ratio to DCM (5 ml), and the reaction mixture was stirred at room temperature for 12 hours. The crude product was purified by column chromatography (CombiFlash Rf 150 purification system, Teledyne Isco, Inc.) with a 40-g high-performance silica column (Teledyne Isco, Inc.) using the following protocol: silica column gradient (DCM/methanol), 0-5 minutes $100 \%(\mathrm{v} / \mathrm{v}) \mathrm{DCM}, 5-30$ minute gradient from $0 \%$ to $10 \%(\mathrm{v} / \mathrm{v})$ methanol. Elution of purified product was monitored by ultraviolet absorption. DCM was removed by rotary evaporation (Rotavapor, Buchi Corporation) and the resulting product lyophilized (SP Scientific VirTis Lyophilizer) for 16 hours to produce a white powder (84\% yield). Infliximab (a monoclonal antibody against hTNF- $\alpha$ ) and bevacizumab (a monoclonal antibody against hVEGF-A) were supplied as a lyophilized powder and reconstituted in sterile water by the $\mathrm{BCH}$ pharmacy according manufacturer recommendations: infliximab (10 $\mathrm{mg} / \mathrm{ml}, 69.4 \mu \mathrm{M})$, bevacizumab $(25 \mathrm{mg} / \mathrm{ml}, 167.6 \mu \mathrm{M})$. Furan-NHS ester was dissolved in DMSO (45 $\mathrm{mg} / \mathrm{ml}, 199.9 \mathrm{mM}$ ) and mixed with the desired aqueous antibody solution by gentle rotation for 2 hours at room temperature. The resulting furan-functionalized antibodies were then purified by dialysis (SlideA-Lyzer, $10-\mathrm{kDa}$ molecular weight cutoff, ThermoFisher Scientific) and stored at $2^{\circ} \mathrm{C}-8^{\circ} \mathrm{C}$ until use.

Functionalization with PEG. First, we coupled maleimide-terminated PEG to PDMS surfaces using trimethoxysilane cross-linking. Segments of platinum-cured PDMS tubing that varied according to aspect ratio (length/inner diameter) were exposed to air plasma generated at 400 mtorr and $12 \mathrm{MHz}$ RF frequency for 120 seconds to produce reactive silanol species via oxidative surface activation $(51,52)$ (Harrick Plasma, PDC-001). Surface oxidation was also carried out by circulation of $\mathrm{H}_{2} \mathrm{O} / 30 \%$ (v/v) $\mathrm{H}_{2} \mathrm{O}_{2} / 12 \mathrm{M} \mathrm{HCl}$ (in a volume ratio of $5: 1: 1)$ through conduits for 1 hour (53) to determine which method of oxidation yielded greater surface oxidation. To add surface amine groups, conduits were filled with $5 \%(\mathrm{v} / \mathrm{v})$ APTMS in acetone, incubated at room temperature for 1 hour (54), flushed with $70 \%$ (v/v) ethanol in water, and purged with dry air. The resulting amine-functionalized conduits were then filled with $0.2 \mathrm{mM} \mathrm{NHS}-\mathrm{PEG}_{\mathrm{n}}-\mathrm{MAL}$ in $1 \times$ PBS (n was either 3 or 10 $\mathrm{kDa}, 0.2 \mathrm{mM}=0.6 \mathrm{mg} / \mathrm{ml}$ for $3-\mathrm{kDa}$ PEG and $2 \mathrm{mg} / \mathrm{ml}$ for $10-\mathrm{kDa} P E G$ ) and incubated at room temperature for 1 hour to facilitate NHS-amine coupling (55). Conduits were then flushed with $10 \mathrm{mM} \mathrm{MES} \mathrm{buffer} \mathrm{(pH}$ 5.5) and purged with dry air. Unbound amine moieties were passivated via acylation (56) by filling maleimide-PEG-modified conduits with $200 \mathrm{mM}$ acetic anhydride in methanol and incubating them at room temperature for 2 hours. Conduits were flushed with 10 mM MES buffer (pH 5.5) and purged with dry air.

Antibody conjugation. Stock solutions of furan-functionalized antibody were diluted in $10 \mathrm{mM}$ MES buffer ( $\mathrm{pH} 5.5$ ) to a concentration of $0.3,0.7,3.4,6.7,10.1$, or $13.4 \mu \mathrm{M}$ (corresponding to $0.05,0.1,0.5$, $1.0,1.5$, and $2.0 \mathrm{mg} / \mathrm{ml}$, respectively), dispensed into maleimide-PEG-modified conduits, and incubated at $37^{\circ} \mathrm{C}$ for 12 hours to facilitate furan-maleimide coupling (57). AMCs endowed with 2 antibodies were prepared by simultaneously introducing $1.7 \mu \mathrm{M}$ anti-hTNF- $\alpha$ antibody (infliximab) and $1.7 \mu \mathrm{M}$ antihVEGF-A antibody (bevacizumab) to maleimide-PEG-modified conduits. Newly formed AMCs were then flushed with, and stored in, sterile PBS $(1 \times, \mathrm{pH} 7.4)$ at $2^{\circ} \mathrm{C}-8^{\circ} \mathrm{C}$ until use.

Fluorescent labeling of surface functionalization. Fluorescent labeling was employed to measure efficacy of surface modification. Following APTMS addition, $1 \mathrm{mg} / \mathrm{ml}$ NHS-fluorescein in PBS (1×, pH 7.4) was dispensed 
into amine-functionalized conduits and incubated at room temperature for 2 hours to facilitate NHS coupling to newly formed surface amines. Conduits were washed with water and ethanol to remove unreacted fluorescein. Efficiency of PEGylation was also measured with fluorescent labeling. SAMSA fluorescein solution (prepared according to the manufacturer's procedure) was instilled into PEGylated conduits with maleimide-functionalized surfaces and incubated at room temperature for 2 hours to enable SAMSA-maleimide coupling. Conduits were then washed with ethanol and soaked in water overnight to remove unreacted SAMSA.

Characterization of AMC function. We developed a method to characterize AMC function (Figure 1C). The system consisted of a fluid reservoir with an inlet and an outlet connected by an AMC. The reservoir was filled with a cytokine-enriched solution of $5 \%(\mathrm{w} / \mathrm{v}) \mathrm{BSA}$ in $1 \times \mathrm{PBS}(\mathrm{pH} 7.4,20 \mathrm{ml})$ and the mixture was circulated through AMCs by a pump at flow rates of 10, 20, 30, or $40 \mathrm{ml} / \mathrm{min}$, depending on the experiment. Samples $(0.5 \mathrm{ml})$ were collected from the reservoir fluid at predetermined time intervals and cytokine concentrations in the fluid were measured by ELISA. Samples were stored at $-80^{\circ} \mathrm{C}$ until analysis. For experiments in which cytokine clearance from blood was studied, human whole blood was used rather than $5 \%$ (w/v) BSA.

AMC function was described in terms of how fast a given cytokine was cleared from test solution (elimination half-life, $\mathrm{T}_{1 / 2}$ ) and how much cytokine was eliminated by surface antibodies (capacity). To determine $\mathrm{T}_{1 / 2}$ and capacity, cytokine concentrations were plotted as a function of time. The resulting curves were fitted to a 1-phase, exponential decay model (GraphPad Prism) and described by the formula $Y$ $=\left(Y_{0}-Y_{\text {saturation }}\right)^{e-K x}+Y_{\text {saturation }}$, where $Y_{0}=$ cytokine concentration $(\mathrm{ng} / \mathrm{ml})$ at time zero, $Y_{\text {saturation }}=$ cytokine concentration after a given AMC is saturated, $K$ is the rate constant $\left(\mathrm{h}^{-1}\right)$, and $x=$ time in hours. $\mathrm{T}_{1 / 2}(\mathrm{~h})$ was determined by $\ln (2) / \mathrm{K}$. AMC capacity was calculated by the equation $C=\left(\left[Y_{0}-Y_{\text {saturation }}\right] \times V\right)$, where $C$ is the capacity of a given AMC in ng and $V$ is the volume of cytokine test solution in $\mathrm{ml}$.

We studied 5 variables that determine AMC function: flow rate through AMCs, antibody concentration used during conjugation, AMC geometry (aspect ratio; length/inner diameter), circulating $\mathrm{pH}$ of fluid, molecular weight of PEG spacer molecules, and AMC surface area. Circulating fluid volumes (20 ml) and flow rates through AMCs were selected to approximate the circulating blood volume of a 400-g rat (58) and the range of target extracorporeal blood flow rates in those rats $(25-100 \mathrm{ml} / \mathrm{kg} / \mathrm{min} ; \sim 10 \%-40 \%$ of rat cardiac output; ref. 31). Such flow rates as a fraction of cardiac output are similar to the range of flow rates in critically ill patients receiving extracorporeal therapies $(\sim 1.9 \mathrm{ml} / \mathrm{kg} / \mathrm{min}$ for continuous renal replacement therapy, ref. 32; up to $100 \mathrm{ml} / \mathrm{kg} / \mathrm{min}$ for extracorporeal membrane oxygenation, ref. 59; these flow rates are $\sim 1.3 \%-100 \%$ of cardiac output in critically ill humans, ref. 60 ). An antibody concentration of 0.1 $\mathrm{mg} / \mathrm{ml}$ has been used in biosensor surfaces (22). We empirically studied a broad range of concentrations above and below $0.1 \mathrm{mg} / \mathrm{ml}$ (40-fold; $0.05-2.0 \mathrm{mg} / \mathrm{ml}$ ) to determine the optimal antibody concentration for AMCs. $\mathrm{pH}$ values were chosen to reflect the physiologic range one would encounter clinically in sepsis. PEG spacers (1.5-3.4 kDa) have been shown to enhance the efficiency of antigen capture by antibodies (22, $30)$; here we tested similarly sized PEG spacers $(3 \mathrm{kDa})$ as well as $10-\mathrm{kDa}$ spacers. AMC geometries were designed with a variety of surface areas and aspect ratios, all with volumes $\leq 4.2 \mathrm{ml}(\sim 15 \%$ of the blood volume for 400-g rats). AMC volume was limited in order to minimize hemodilution when the saline-containing AMC would be connected to the bloodstream in subsequent in vivo experiments.

To validate AMC function in circulating blood, reservoirs were filled with heparinized human whole blood $(20 \mathrm{ml})$ and circulated through AMCs (20 ml/min). A cytokine-enriched solution of 5\% (w/v) BSA was continuously infused into the reservoir. The concentration and flow rate of the cytokine infusion solution were chosen to obtain the desired rate of rise in cytokine concentration in blood over time, while simultaneously replacing the volume of blood lost to sampling over the course of the experiment. Samples $(0.5 \mathrm{ml})$ were collected from the reservoir at predetermined intervals and immediately centrifuged (Microfuge $22 \mathrm{R}$ microcentrifuge, Beckman Coulter Life Sciences; 4,000 rpm [ 1400 g] at $4^{\circ} \mathrm{C}$ for 15 minutes). The supernatant (plasma) was transferred into microcentrifuge tubes, frozen in liquid nitrogen, and stored at $-80^{\circ} \mathrm{C}$ until analysis. Plasma cytokine concentrations were measured by ELISA.

Surgical preparation and LPS injection. Adult, male Sprague-Dawley rats weighing 413-599 g were housed in groups, in a $6 \mathrm{am} / 6 \mathrm{pm}$ light/dark cycle. Under general anesthesia with an isoflurane-oxygen mixture, the left femoral vein (LFV) was dissected, isolated, and cannulated with a 22-gauge Jelco angiocatheter (length 25 $\mathrm{mm}$, inner diameter $0.95 \mathrm{~mm}$ ) in sterile fashion. (Postmortem dissection revealed that catheter tips terminated in the inferior vena cava [IVC] caudal to the renal veins). The catheter was sutured in place and the wound was closed with simple interrupted sutures. Rats were then given a single intravenous dose of LPS (17.5 mg/ $\mathrm{kg}$ ) derived from Escherichia coli 0127:B8 diluted in $0.5 \mathrm{ml}$ of $0.9 \%$ saline. The right femoral artery (RFA) was 
then dissected, isolated, and cannulated with a 24-gauge Jelco angiocatheter (length $18 \mathrm{~mm}$, inner diameter $0.75 \mathrm{~mm}$ ). The catheter was sutured in place and the wound was closed with simple interrupted sutures. The right external jugular vein (REJV) was dissected, isolated, and cannulated via the Seldinger technique with a 22-gauge Jelco angiocatheter (length $25 \mathrm{~mm}$, inner diameter $0.95 \mathrm{~mm}$ ), platinum-tipped Nitinol guidewire (Cook Medical; length $40 \mathrm{~cm}$, diameter $0.046 \mathrm{~cm}$ ), and $4.0 \mathrm{~F}$ (18 gauge) $\times 6 \mathrm{~cm}$ catheter (Cook Medical). REJV catheters were inserted to a depth of approximately $2 \mathrm{~cm}$ (postmortem dissection demonstrated catheter tips to be in the right atrium at this depth). When the catheter terminated in the right atrium, blood return was brisk. The catheter was sutured in place and the wound was closed with a single suture. Heparin boluses ( 50 units $=0.5 \mathrm{ml} ; 100 \mathrm{units} / \mathrm{ml})$ were administered into each catheter immediately after their placement. The heparin bolus into the LFV was given immediately after LPS injection.

$E B P$. The REJV catheter was connected to the venous limb of the circuit to drain blood from the right atrium and the LFV catheter to the arterial limb for return of purified blood into the IVC. The circuit was composed of 8 components (listed in order from inflow into the circuit to outflow into the rat): extension tubing (Baxter Healthcare Corporation; $17 \mathrm{~cm}, 0.26 \mathrm{ml}$ volume), 3-way stopcock (Baxter Healthcare Corporation), unmodified platinum-cured silicone tubing (Cole-Parmer; $43.2 \mathrm{~cm}$, inner diameter $0.16 \mathrm{~cm}$, approximately $0.9 \mathrm{ml}$ volume) connected to a roller pump (ThermoFisher Scientific), 5-ml water-jacketed bubble trap compliance chamber (Radnoti LLC; filled to approximately $1 \mathrm{ml}$ of circulating blood at any given time), AMC ( $88.9 \mathrm{~cm}$, inner diameter $0.16 \mathrm{~cm}$, approximately $1.8 \mathrm{ml}$ volume), 3-way stopcock, and extension tubing $(17 \mathrm{~cm}, 0.26 \mathrm{ml}$ volume). The total extracorporeal circulating volume was approximately $4.2 \mathrm{ml}$, or $14.4 \% \pm$ $1.9 \%$ of the rat circulating blood volume (58). During cannulation, $70 \%$ (v/v) ethanol was circulated through circuits (minus the AMC segment) to sterilize them. Once cannulation was completed, ethanol was drained and AMCs were incorporated. Circuits were then primed with approximately $4.2 \mathrm{ml}$ of $0.9 \%$ saline.

Animals were randomized to undergo extracorporeal circulation through either anti-rIL-1 $\beta$ conduits or anti-hVEGF-A conduits. The latter do not filter rVEGF-A (see results). Investigators were blinded to treatment group. To prevent the development of hypotension from rapid initiation of extracorporeal circulation, flow was gradually increased to the maximum flow rate over 10 minutes such that full flow was established 60 minutes after LPS injection (see next paragraph for details of how full flow was quantified). Heparin (diluted to 50 units/ $\mathrm{ml}$ in $0.9 \%$ saline) was administered via continuous intravenous infusion ( $2.7 \mathrm{units} / \mathrm{kg} / \mathrm{min}$; ref. 61$)$ into the IVC via the 3-way stopcock immediately distal to the AMC. Saline $(0.9 \%)$ was continuously infused into the arterial catheter to maintain patency. The combined total fluid rate (heparin and arterial line infusions) was $100 \mathrm{ml} / \mathrm{kg}$ / day. Treatment with AMCs was continued for 12 hours or until death (whichever came first).

Calibration of blood flow rate through extracorporeal circuits. To determine how fast blood flowed through extracorporeal circuits, a complete circuit/pump system was used to drain a known quantity of whole blood (porcine, donated from the animal research program at $\mathrm{BCH}$; measured hemoglobin and hematocrit $8.8 \mathrm{~g} / \mathrm{dl}$ and $26 \%$, respectively) from one graduated cylinder into another. Once full flow was established, 2 observers measured with stop watches how long it took to decrease the volume of blood by $1 \mathrm{ml}$ for 10 consecutive measurements (i.e., $10 \mathrm{ml}$ ) to determine the mean $\pm \mathrm{SD}$ flow rate through circuits in $\mathrm{ml} / \mathrm{min}$.

Cytokine and biochemical measurements. Blood samples were obtained from the arterial line for cytokine measurement 1 hour after LPS injection $(400 \mu 1)$, and every 2 hours thereafter $(200 \mu 1)$ for cytokine measurement. Blood was centrifuged at 4,000 rpm $(\sim 1400 \mathrm{~g})$ for 15 minutes at $4^{\circ} \mathrm{C}$ (Allegra X-22R, Beckman Coulter Inc.). The plasma (supernatant) was collected, frozen with in liquid nitrogen, and stored at $-80^{\circ} \mathrm{C}$ until analysis. Rat plasma cytokine concentrations were measured by the Cytokine Reference Laboratory (University of Minnesota, Minneapolis, Minnesota, USA). A final blood sample was taken 13 hours after LPS injection (predetermined end of experiment) or at time of death (whichever came first) to measure arterial blood $\mathrm{pH}$ and blood glucose (VetScan i-STAT 1, Abaxis Inc.).

Statistics. Cytokine concentrations, $\mathrm{T}_{1 / 2}$, and total cytokine capacity values were reported as means and SDs of $n$ observations (sample sizes for each experimental group are displayed in Supplemental Tables 1-5). Unless otherwise noted, comparisons were made using 1-way analysis of variance (ANOVA). When the Student's $t$ test was used, it was unpaired and 2-tailed. The $P$ value required for statistical significance $(\alpha)$ was 0.05 . Graphing and statistical analyses were performed with Prism 6.0 (GraphPad Software Inc.).

Study approval. Animals were cared for in accordance with protocols approved by the Institutional Animal Care and Use Committee at $\mathrm{BCH}$, as well as the Guide for the Care and Use of Laboratory animals of the US National Research Council. 


\section{Author contributions}

JBM was responsible for study design, conducting experiments, acquiring data, analyzing data, and writing the manuscript. RGW was responsible for study design, conducting experiments, acquiring data, and editing the manuscript. KR was responsible for analyzing data and writing the manuscript. MTN, CKL, MM, AS, $\mathrm{PA}, \mathrm{JY}, \mathrm{AML}$, and SO were responsible for conducting experiments and acquiring data. NVV assisted in developing the surgical methods for the in vivo model. RK was responsible for analyzing data and developing the mathematical model. DSK was responsible for study design, analyzing data, and writing the manuscript.

\section{Acknowledgments}

We thank David Zurakowski (Department of Anesthesiology, Boston Children's Hospital) for providing assistance with statistical analysis. This work was supported by grants from the Technology and Innovation Development Office at Boston Children's Hospital and the Boston Biomedical Innovation Center (grant number U54HL119145). RGW would like to thank the Natural Sciences and Research Council of Canada.

Address correspondence to: Daniel S. Kohane, Children's Hospital Boston, Bader 628, 300 Longwood Avenue, Boston, Massachusetts 02115, USA. Phone: 617.355.7327; Email: daniel.kohane@childrens.harvard.edu.

RGW's present address is: Department of Chemistry and Chemical Biology, McMaster University, Hamilton, Ontario, Canada.

1. Rimmelé T, Kellum JA. Clinical review: blood purification for sepsis. Crit Care. 2011;15(1):205.

2. Zhou F, Peng Z, Murugan R, Kellum JA. Blood purification and mortality in sepsis: a meta-analysis of randomized trials. Crit Care Med. 2013;41(9):2209-2220.

3. Kellum JA, Venkataraman R, Powner D, Elder M, Hergenroeder G, Carter M. Feasibility study of cytokine removal by hemoadsorption in brain-dead humans. Crit Care Med. 2008;36(1):268-272.

4. Seghaye M, et al. Interleukin-10 release related to cardiopulmonary bypass in infants undergoing cardiac operations. $J$ Thorac Cardiovasc Surg. 1996;111(3):545-553.

5. de Jong PR, et al. STAT3 regulates monocyte TNF-alpha production in systemic inflammation caused by cardiac surgery with cardiopulmonary bypass. PLoS One. 2012;7(4):e35070.

6. Langgartner J, Vasold A, Glück T, Reng M, Kees F. Pharmacokinetics of meropenem during intermittent and continuous intravenous application in patients treated by continuous renal replacement therapy. Intensive Care Med. 2008;34(6):1091-1096.

7. Zöllner S, Pablik E, Druml W, Derfler K, Rees A, Biesenbach P. Fibrinogen reduction and bleeding complications in plasma exchange, immunoadsorption and a combination of the two. Blood Purif. 2014;38(2):160-166.

8. Rhodes A, et al. Surviving Sepsis Campaign: International Guidelines for Management of Sepsis and Septic Shock: 2016. Crit Care Med. 2017;45(3):486-552.

9. Ogura H, et al. SIRS-associated coagulopathy and organ dysfunction in critically ill patients with thrombocytopenia. Shock. 2007;28(4):411-417.

10. Hotchkiss RS, Karl IE. The pathophysiology and treatment of sepsis. N Engl J Med. 2003;348(2):138-150.

11. Hotchkiss RS, Monneret G, Payen D. Sepsis-induced immunosuppression: from cellular dysfunctions to immunotherapy. Nat Rev Immunol. 2013;13(12):862-874.

12. Hotchkiss RS, Monneret G, Payen D. Immunosuppression in sepsis: a novel understanding of the disorder and a new therapeutic approach. Lancet Infect Dis. 2013;13(3):260-268.

13. Malmstrøm ML, et al. Cytokines and organ failure in acute pancreatitis: inflammatory response in acute pancreatitis. Pancreas. 2012;41(2):271-277

14. Sosa RA, et al. Early cytokine signatures of ischemia/reperfusion injury in human orthotopic liver transplantation. JCI Insight. 2016;1(20):e89679.

15. Finnerty CC, et al. Temporal cytokine profiles in severely burned patients: a comparison of adults and children. Mol Med. 2008;14(9-10):553-560.

16. Shein SL, et al. Hemorrhagic shock shifts the serum cytokine profile from pro- to anti-inflammatory after experimental traumatic brain injury in mice. J Neurotrauma. 2014;31(16):1386-1395.

17. Chen $\mathrm{P}$, et al. Multiplex serum cytokine immunoassay using nanoplasmonic biosensor microarrays. ACS Nano. 2015;9(4):4173-4181.

18. Hirai S. Systemic inflammatory response syndrome after cardiac surgery under cardiopulmonary bypass. Ann Thorac Cardiovasc Surg. 2003;9(6):365-370.

19. Lord JM, et al. The systemic immune response to trauma: an overview of pathophysiology and treatment. Lancet. 2014;384(9952):1455-1465.

20. Singer M, et al. The Third International Consensus Definitions for Sepsis and Septic Shock (Sepsis-3). JAMA. 2016;315(8):801-810.

21. Horeczko T, Green JP, Panacek EA. Epidemiology of the systemic inflammatory response syndrome (SIRS) in the emergency department. West J Emerg Med. 2014;15(3):329-336.

22. Cao T, et al. Investigation of spacer length effect on immobilized Escherichia coli pili-antibody molecular recognition by AFM. Biotechnol Bioeng. 2007;98(6):1109-1122.

23. Bozza FA, et al. Cytokine profiles as markers of disease severity in sepsis: a multiplex analysis. Crit Care. 2007;11(2):R49. 
24. Mera S, et al. Multiplex cytokine profiling in patients with sepsis. APMIS. 2011;119(2):155-163.

25 . Yano K, et al. Vascular endothelial growth factor is an important determinant of sepsis morbidity and mortality. $J$ Exp Med. 2006;203(6):1447-1458.

26. Zhang J, et al. Effects of hemoadsorption with a novel adsorbent on sepsis: in vivo and in vitro study. Blood Purif. 2015;39(13):239-245.

27. DiLeo MV, Fisher JD, Burton BM, Federspiel WJ. Selective improvement of tumor necrosis factor capture in a cytokine hemoadsorption device using immobilized anti-tumor necrosis factor. J Biomed Mater Res Part B Appl Biomater. 2011;96(1):127-133.

28. Kellum JA, Song M, Venkataraman R. Hemoadsorption removes tumor necrosis factor, interleukin-6, and interleukin-10, reduces nuclear factor-kappaB DNA binding, and improves short-term survival in lethal endotoxemia. Crit Care Med. 2004;32(3):801-805.

29. De Vriese AS, Colardyn FA, Philippé JJ, Vanholder RC, De Sutter JH, Lameire NH. Cytokine removal during continuous hemofiltration in septic patients. J Am Soc Nephrol. 1999;10(4):846-853.

30. Weimer BC, Walsh MK, Wang X. Influence of a poly-ethylene glycol spacer on antigen capture by immobilized antibodies. J Biochem Biophys Methods. 2000;45(2):211-219.

31. Conzen PF, Vollmar B, Habazettl H, Frink EJ, Peter K, Messmer K. Systemic and regional hemodynamics of isoflurane and sevoflurane in rats. Anesth Analg. 1992;74(1):79-88.

32. RENAL Replacement Therapy Study Investigators, et al. Intensity of continuous renal-replacement therapy in critically ill patients. NEngl J Med. 2009;361(17):1627-1638.

33. Noritomi DT, et al. Metabolic acidosis in patients with severe sepsis and septic shock: a longitudinal quantitative study. Crit Care Med. 2009;37(10):2733-2739.

34. Remick DG, Newcomb DE, Bolgos GL, Call DR. Comparison of the mortality and inflammatory response of two models of sepsis: lipopolysaccharide vs. cecal ligation and puncture. Shock. 2000;13(2):110-116.

35. Gogos CA, Drosou E, Bassaris HP, Skoutelis A. Pro- versus anti-inflammatory cytokine profile in patients with severe sepsis: a marker for prognosis and future therapeutic options. J Infect Dis. 2000;181(1):176-180.

36. Muenzer JT, et al. Characterization and modulation of the immunosuppressive phase of sepsis. Infect Immun. 2010;78(4):1582-1592.

37. Kellum JA, et al. Understanding the inflammatory cytokine response in pneumonia and sepsis: results of the Genetic and Inflammatory Markers of Sepsis (GenIMS) Study. Arch Intern Med. 2007;167(15):1655-1663.

38. Wong HR, et al. Toward a clinically feasible gene expression-based subclassification strategy for septic shock: proof of concept. Crit Care Med. 2010;38(10):1955-1961.

39. Panacek EA, et al. Efficacy and safety of the monoclonal anti-tumor necrosis factor antibody F(ab')2 fragment afelimomab in patients with severe sepsis and elevated interleukin-6 levels. Crit Care Med. 2004;32(11):2173-2182.

40. Abraham E, et al. Efficacy and safety of monoclonal antibody to human tumor necrosis factor alpha in patients with sepsis syndrome. A randomized, controlled, double-blind, multicenter clinical trial. TNF-alpha MAb Sepsis Study Group. JAMA. 1995;273(12):934-941.

41. Opal SM, et al. Confirmatory interleukin-1 receptor antagonist trial in severe sepsis: a phase III, randomized, double-blind, placebo-controlled, multicenter trial. The Interleukin-1 Receptor Antagonist Sepsis Investigator Group. Crit Care Med. 1997;25(7):1115-1124.

42. Abraham E, et al. Double-blind randomised controlled trial of monoclonal antibody to human tumour necrosis factor in treatment of septic shock. NORASEPT II Study Group. Lancet. 1998;351(9107):929-933.

43. Fisher CJ, et al. Initial evaluation of human recombinant interleukin-1 receptor antagonist in the treatment of sepsis syndrome: a randomized, open-label, placebo-controlled multicenter trial. Crit Care Med. 1994;22(1):12-21.

44. Feldschuh J, Enson Y. Prediction of the normal blood volume. Relation of blood volume to body habitus. Circulation. 1977;56(4):605-612.

45. Xu H, Lu JR, Williams DE. Effect of surface packing density of interfacially adsorbed monoclonal antibody on the binding of hormonal antigen human chorionic gonadotrophin. J Phys Chem B. 2006;110(4):1907-1914.

46. Peng ZY, Carter MJ, Kellum JA. Effects of hemoadsorption on cytokine removal and short-term survival in septic rats. Crit Care Med. 2008;36(5):1573-1577.

47. Schädler D, et al. The effect of a novel extracorporeal cytokine hemoadsorption device on IL-6 elimination in septic patients: A randomized controlled trial. PLoS One. 2017;12(10):e0187015.

48. Ho HC, Chapital AD, Yu M. Hypothyroidism and adrenal insufficiency in sepsis and hemorrhagic shock. Arch Surg. 2004;139(11):1199-1203.

49. Otto GP, et al. The late phase of sepsis is characterized by an increased microbiological burden and death rate. Crit Care. 2011;15(4):R183.

50. Torgersen C, et al. Macroscopic postmortem findings in 235 surgical intensive care patients with sepsis. Anesth Analg. 2009;108(6):1841-1847.

51. Lee JN, Park C, Whitesides GM. Solvent compatibility of poly(dimethylsiloxane)-based microfluidic devices. Anal Chem. 2003;75(23):6544-6554.

52. Millare B, Thomas M, Ferreira A, Xu H, Holesinger M, Vullev VI. Dependence of the quality of adhesion between poly(dimethylsiloxane) and glass surfaces on the conditions of treatment with oxygen plasma. Langmuir. 2008;24(22):13218-13224.

53. Sui G, et al. Solution-phase surface modification in intact poly(dimethylsiloxane) microfluidic channels. Anal Chem. 2006;78(15):5543-5551.

54. Séguin C, McLachlan J, Norton P, Lagugné-Labarthet F. Surface modification of poly (dimethylsiloxane) for microfluidic assay applications. Appl Surf Sci. 2010;256(8):2524-2531.

55. Scott MA, Wissner-Gross ZD, Yanik MF. Ultra-rapid laser protein micropatterning: screening for directed polarization of single neurons. Lab Chip. 2012;12(12):2265-2276

56. Naik S, Bhattacharjya G, Talukdar B, Patel B. Chemoselective acylation of amines in aqueous media. Eur J Org Chem. 2004;2004(6):1254-1260.

57. Gandini A. The furan/maleimide Diels-Alder reaction: A versatile click-unclick tool in macromolecular synthesis. Prog Polym Sci. 2013;38(1):1-29. 
58. Lee HB, Blaufox MD. Blood volume in the rat. J Nucl Med. 1985;26(1):72-76.

59. Butt W, Heard M, Peek GJ. Clinical management of the extracorporeal membrane oxygenation circuit. Pediatr Crit Care Med. 2013;14(5 Suppl 1):S13-S19.

60. Sakka SG, Reinhart K, Wegscheider K, Meier-Hellmann A. Comparison of cardiac output and circulatory blood volumes by transpulmonary thermo-dye dilution and transcutaneous indocyanine green measurement in critically ill patients. Chest. 2002;121(2):559-565.

61. Bjornsson TD, Levy G. Pharmacokinetics of heparin. II. Studies of time dependence in rats. J Pharmacol Exp Ther. $1979 ; 210(2): 243-246$ 